Special issue of the 2nd International Conference on Computational and Experimental Science and Engineering (ICCESEN 2015)

\title{
Effects of Blanking Speed on the Shear Surface of Mild Steel (St37)
}

\author{
E. KAnCA ${ }^{a}$, O. EyercioĞLU ${ }^{b}$, I.H. KARAhan ${ }^{c}$, A. GÜnen ${ }^{d, *}$ And K. GÖV ${ }^{b}$ \\ ${ }^{a}$ Iskenderun Tech. Univ., Faculty of Mechanics, Mechanical Engineering Department, Hatay, Turkey \\ ${ }^{b}$ University of Gaziantep, Mechanical Engineering Department, Gaziantep, Turkey \\ ${ }^{c}$ Mustafa Kemal University, Faculty of Science and Arts, Department of Physics, Hatay, Turkey \\ ${ }^{d}$ Iskenderun Tech. Univ., Faculty of Technology, Materials Engineering Department, Hatay, Turkey
}

\begin{abstract}
Blanking operation is widely used to cut sheet or plates by a shearing process between punch and die. The process of shearing and the conditions of the sheared surface are influenced by the punch, the die, the speed of punching the clearance between the punch and the die. In this study, effects of high speed blanking on surface quality and corrosion properties of mild steel St37 shear surface have been investigated. The work presented in this paper aims at evaluating the shear surface quality improvements of the St37 resulting from the use of high energy rate forging machine. The appraisal is based on criteria related to surface accuracy and corrosion resistance characterization. For this purpose, St37 mild steels were cut using three different punch speeds hydraulic presses at nearly quasistatic, conventional mechanical presses at low punch velocity $(0.2 \mathrm{~m} / \mathrm{s})$ and high energy rate forging machine at high punch velocity $(10 \mathrm{~m} / \mathrm{s})$, for different die clearances $(4.5 \%-6 \%$ of sheet thickness). After accelerated corrosion tests, blanks were performed in conjunction with scanning electron microscopy technique to study the cutting process of the blanks at room temperature. In fact, by using high energy rate forging machine, a reduction of more than $25 \%$ of the surface roughness $\left(R_{\mathrm{a}}\right)$ was realized and better resistance to stress corrosion cracking and pitting corrosion was noticed. It was observed that the corrosion resistance of the high energy rate forging-cut specimen was better than that of the hydraulic-cut and mechanical-cut specimens.
\end{abstract}

DOI: 10.12693/APhysPolA.130.370

PACS/topics: 81.05.Bx, 82.35.Gh, 81.65.Kn

\section{Introduction}

Blanking process is widely used in the industrial parts and the use of the process in the manufacturing of small and light components is increased because the desired shape, size and finishing products can be obtained easily [1]. Blanking is a constrained shearing operation that involves elastic deflection, plastic deformation, shearing (cutting) and fracture of the work material. Compared with other processes of metal forming, the aim of the blanking process is not only to make the metal deform to perfect shape and dimensions but also to break the sheet metal [2]. In the blanking processes, clearance and shape of shearing edge are two main parameters of major concern in the shearing operation. It is fact that the quality of the blank surface is affected by the magnitude of the clearance between punch and die. Literature claims that large clearances cause extensive plastic deformations adjacent to the shear region and punch corner. Generally, clearance value lies in between 4 and $12 \%$ of the blank thickness. The clearance usually decreases with increase ductility [3].

Mild steel is widely used as a structural material in a number of engineering applications because of its good machinability, high thermal conductivity and superior mechanical strength. However, it is highly prone to suffer from corrosion and wear as a consequence of which its service life is limited. Therefore, a number of approaches have been adopted to improve its corrosion and wear resistance properties [4].

The key issue related to the corrosion resistance is the stability and electrical behavior of the protective surface oxide layer on the steel surface. This may be investigated with a number of electrochemical methods such as polarization method. Several studies were performed to improve corrosion resistance of mild steel. For example, in the study of Shukla et al. [5] a commercially available drug is used as corrosion inhibitor for mild steel in hydrochloric acid solution. The others were used with film coating to improve the corrosion resistance of mild steel $[4,6]$. However, little research has been carried out on the quality of shear-fractured surface and corrosion resistance enhancement of mild steel by high punch speeds. Yaldiz et al. [7] and Davies and Dhavan [8] showed that the quality of shear-fractured surface improved and the amount of distortion reduced as a result of the use of high punch speeds. Therefore, the research needs to be focused on the corrosion behavior of shear surface of mild steel at high punching speeds.

The objective of the present study is to investigate the impact of high punching speeds on the shear surface corrosion behavior of mild steel. For this purpose, St37 mild steels were cut used three different punch speeds hydraulic presses (HP) at nearly quasistatic, conventional mechanical presses $(\mathrm{CP})$ at low punch velocity $(0.2 \mathrm{~m} / \mathrm{s})$ and high energy rate forming (HERF) machine at high punch velocity $(10 \mathrm{~m} / \mathrm{s})$, for different die clearances $(4.5 \%-6 \%$ of sheet thickness).

\subsection{Cutting theory}

The blanking is a classical separation process. As shown in Fig. 1, the blanking process is divided into four phases with fundamentally different physical behavior and numerical treatment. The first phase is elastic 
deformation. When a sufficient load is applied onto a sheet metal, it will cause the shape change of sheet metal. This change is called deformation. A temporary shape change that is self-reversing after the force is removed, so that the sheet metal returns to original shape, is called elastic deformation. This type of deformation involves stretching of the bonds, but the atoms do not slip past the each other. When the stress is sufficient to permanently deform the sheet metal, plastic deformation begins, which is the second phase. Plastic deformation involves the breaking of a limited number of atomic bonds by the movement of the dislocations. The third phase is the shearing deformation phase, in which the extruding depth of sheet increases gradually, whilst the tensile stress and bending moment in the material continue to increase. The material in the deforming section will suffer work hardening. The blanking force continues to increase until cracks occur in the sheet near to the cutting edges. When the cracks appear, the third phase will finish and the fourth phase, namely fracture separation, will begin. The punch still continues to penetrate into sheet, and the cracks near to cutting edges of the punch and the die become larger and expand into the material. When the cracks at top and bottom meet and coincide, the sheet will be fracture [9-12].

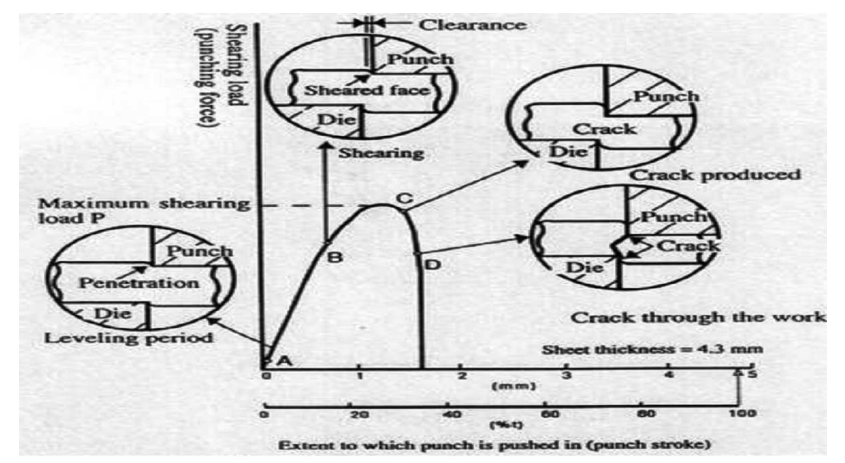

Fig. 1. Schematic view of blanking process.

\section{Experimental}

2.1. Material

St37 mild steel is used as a material in this investigation. The chemical composition and mechanical properties of the examined $3.5 \mathrm{~mm}$ thickness mild steel are presented in Table I.

TABLE I

Chemical composition (wt\%) and mechanical properties of St37 mild steel.

\begin{tabular}{|c|c|c|c|c|c|}
\hline $\mathrm{C}$ & $\mathrm{Si}$ & $\mathrm{Mn}$ & $\mathrm{P}$ & $\mathrm{S}$ & Other \\
\hline 0.17 & 0.30 & 0.40 & 0.04 & 0.05 & 0.00 \\
\hline \multicolumn{2}{|c|}{$\begin{array}{c}\text { Hardness } \\
{[\mathrm{HVN}]}\end{array}$} & $\begin{array}{l}\text { Tensile st. } \\
{[\mathrm{MPa}]}\end{array}$ & $\begin{array}{c}\text { Elongation } \\
{[\%]}\end{array}$ & \multicolumn{2}{|c|}{$\begin{array}{l}\text { Yield strength } \\
{[\mathrm{MPa}]}\end{array}$} \\
\hline \multicolumn{2}{|c|}{15} & 360 & 24 & \multicolumn{2}{|c|}{24} \\
\hline
\end{tabular}

\subsection{Machines}

In this study in order to acquire high punch speed, a prototype HERF machine was designed and constructed. In order to identify the performance of the designed and manufactured HERF machine, the location change of the hammer with time must be determined. The change in the location of the fixed magnet is detected by a magnetic scale. The loadcell placed under the lower die provides the value of the load transferred to workpiece. A data collection device $\left(10^{6} \mathrm{data} / \mathrm{s}\right)$ is used so as to transfer the data from the magnetic ruler and the loadcell to a computer. A schematic view of the magnetic scale, the loadcell, and the connection of data collection devices are given in Fig. 2. It was observed that prototype machine can reach the $10 \mathrm{~m} / \mathrm{s}$ punch velocity so it can be called as HERF machine. As it is known if a machine had higher than $5 \mathrm{~m} / \mathrm{s}$ punch velocity, it can be called as HERF machine [12].

St37 mild steel was cut with three different types of cutting machines, namely $\mathrm{HP}$ at nearly quasistatic $(0.01 \mathrm{~m} / \mathrm{s}), \mathrm{CP}$ at low punch velocity $(0.2 \mathrm{~m} / \mathrm{s})$, and HERF at high punch velocity $(10 \mathrm{~m} / \mathrm{s})$.

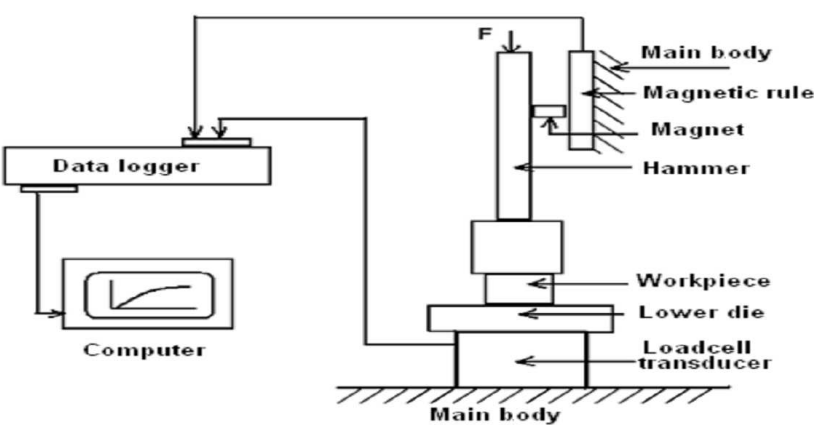

Fig. 2. Schematic connection views of magnetic rule, loadcell transducer and data-logger.

\subsection{Blanking die}

As seen in Fig. 3, the tool used in experiments is made of two parts, which are dies and the punch. The mechanical and thermal properties of the die material SAE 4140 is presented in Table II. SAE 4140 is hardened by implying the heat treatment process. Four different die were created by changing their clearances $(4.5 \%, 5 \%, 5.5 \%$, $6 \%$ of sheet thickness).

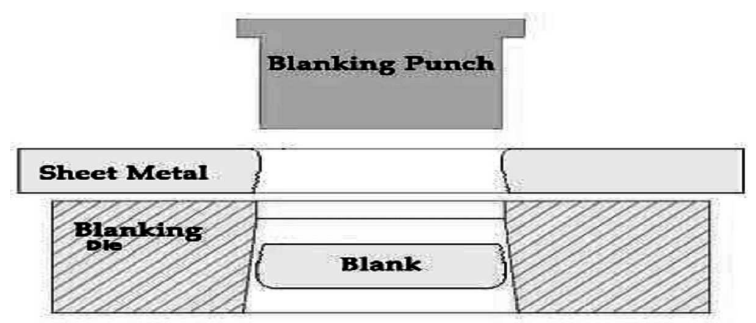

Fig. 3. Schematic views of the blanking die, sheet metal and punch. 
TABLE II

Mechanical and thermal properties of the specifications of the die material SAE 4140.

\begin{tabular}{c|c}
\hline \hline yield stress & $650 \mathrm{mpa}$ \\
maximum elongation & $12 \%$ \\
hardening temp. for quenc. in water & $820-860^{\circ} \mathrm{C}$ \\
hardening temp. for quenc. in oil & $820-860^{\circ} \mathrm{C}$ \\
Vickers hardness & $560 \mathrm{hv}$
\end{tabular}

\subsection{Measurements}

\subsubsection{Surface roughness}

The surface roughness was evaluated using a Talysurf stylus-type profile meter. The surface roughness values of cutting and fracture surfaces were central-line average $\left(R_{\mathrm{a}}\right)$, and were used to evaluate the quality of the specimen surface. Each surface roughness was determined by averaging ten measurements done at various portions on the surface for each blanking condition.

\subsubsection{Corrosion test}

Accelerated corrosion tests were performed with the blanks cut at different speeds and clearances. Blanks (working electrodes, WE) were polished with silicon carbide papers from 3 through 1 to $0.5 \mu \mathrm{m}$ and velvet, rinsed with the twice distilled water, washed in acetone, rinsed with the twice distilled water again and then dried in air. Counter electrode was a $\mathrm{Pt}$ gauze electrode for corrosion measurements. The reference electrode used in all experiments was a saturated calomel electrode (SCE). All the potentials are referred against SCE.

The electrochemical behaviors of the specimens were analyzed in $3.5 \mathrm{wt} \% \mathrm{NaCl}$ aqueous solution at room temperature in a Pyrex glass cell. The corrosion behaviors of the blanks were investigated by a potentiodynamic polarization technique. Polarization measurements were performed with an electrochemical analyzer/workstation (Model 1100, CH Instruments, USA) with a three-electrode configuration. The exposed area of the specimens was about $0.5 \mathrm{~cm}^{2}$. The specimens were covered with a cold setting resin and immersed into the solution until a steady OCP was reached. At least four parallel measurements were done with freshly polished blanks. After polarization, the specimens were cleaned mechanically for SEM observations by using a JEOL 6390 SEM. The results of the corrosion tests were evaluated using $E_{\text {corr }}$ values obtained from the polarization curves.

\section{Results and discussion}

\subsection{Effects of high speed blanking on the mild steel shear surface quality}

The micro-geometrical quality of the shear and fracture surfaces were characterized by the average $\left(R_{\mathrm{a}}\right)$ roughness parameter. Figure 4 presents the relationship among three different types of cutting machines with using four different clearance die which cut $3.5 \mathrm{~mm}$ thickness mild steel specimens and their shear and fracture surface roughness. From Fig. 4, it is clear that the increase in cutting speed has a tendency of improving both cutting and fracture surfaces. The best cutting and fracture surface was obtained at the $5,5.5$, and $6 \%$ clearance by using HERF, CP, and HP, respectively.

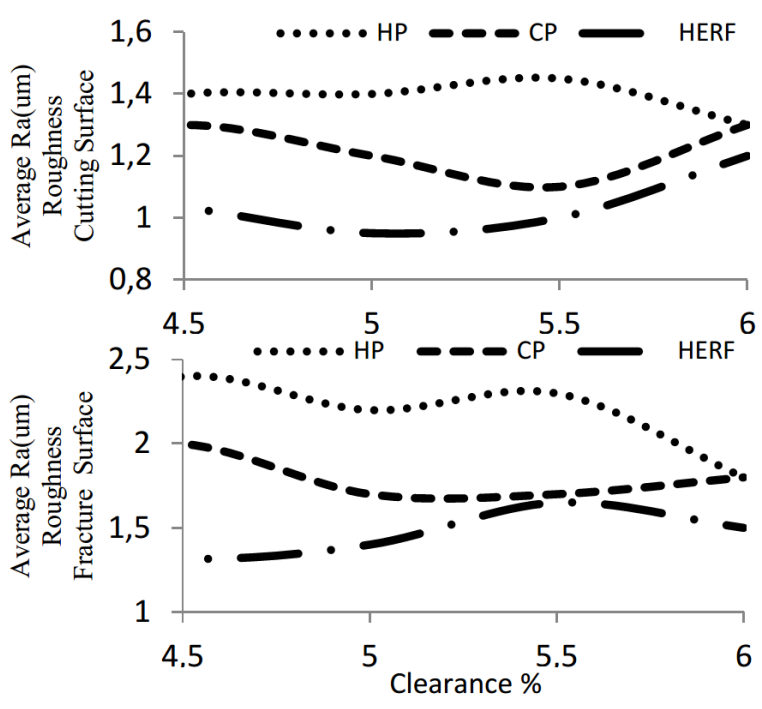

Fig. 4. Relationship among the three different types of cutting machines with using four different die clearances: (a) cutting surface, (b) fracture surface.

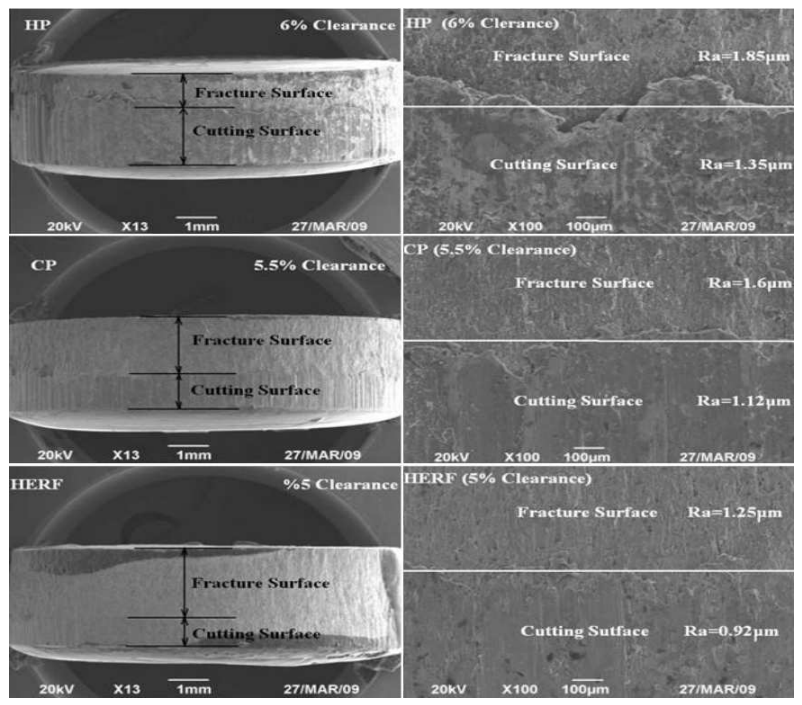

Fig. 5. SEM views of the shear and fracture region of the blanks obtained from machines with different punching speeds.

Surface and detailed SEM views of the shear and fracture region of the blanks obtained from machines with different punching speeds are provided in Fig. 5. The best roughness values depending on the clearance for the each machine type are presented in Fig. 5. As the punching rate increased, a decrease in roughness value in the shear and fracture region was observed. When compared to the hydraulic and eccentric pressing done with HERF, a decrease of $28 \%$ and $15 \%$ in the fracture area and of $20 \%$ and $6 \%$ in the shear area was observed. 


\subsection{Effects of high speed punching} on the mild steel shear surface corrosion

The sheared surface of the blanks were subjected to corrosion in $3.5 \% \mathrm{NaCl}$ solution and potential corrosion graphics are given in Fig. 6. The corrosion resistance in shearing with HP (a) increased in direct proportion with clearance and the shear performed in $6 \%$ die clearance reflected the best corrosion properties. In other shears, too, the clearance proportion of $4.5 \%$ showed poor corrosion properties, while the shear performed with a die clearance of $5.5 \%$ in mechanical presses (b) and $5 \%$ in HERF (c) reflected the best corrosion properties.
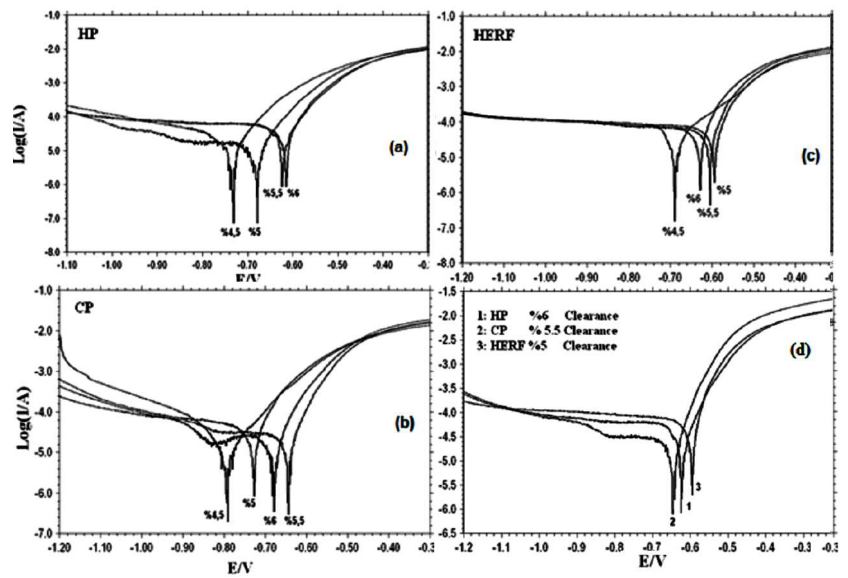

Fig. 6. Potential corrosion graphics of the blanks produced in different clearances for (a) hydraulic, (b) conventional, (c) HERF, (d) the best corrosion rate for each shearing technique.

The corrosion potential in shear done with hydraulic press $\left(E_{\text {corr }}\right)$ is $-0.615 \mathrm{~V}$ (SCE) for the blank with a clearance of $6 \%$, while it is $-0.730 \mathrm{~V}$ for the blank with a die clearance of $4.5 \%$. Compared to the blank with a die clearance of $4.5 \%$, the blank with a die clearance of $6 \%$ is $18 \%$ more corrosion resistant. In blanks formed with eccentric press, the lowest corrosion potential was observed in the blank with a die clearance of $4.5 \%$ $(-0.790 \mathrm{~V})$, whereas the highest potential was recorded for the blank with $5.5 \%$ die clearance $(-0.643 \mathrm{~V})$. There is a $23 \%$ improvement between the two blanks. In blanks shaped with high energy, the lowest corrosion potential is $-0.689 \mathrm{~V}$ for blanks of $4.5 \%$ die clearance, while the highest resistance $(-0.594)$ was observed in the blank with a die clearance of $5 \%$, and thus a corrosion potential difference of $16 \%$ occurred.

The corrosion potential of all blanks is given in Table III. The comparison of the blanks that give the best corrosion rate for each shearing technique is given in Fig. 6d. In all the die clearances that were tested, the corrosion potential of the blanks that were formed with HERF press was found to be favorable. Post-experiment SEM views of the shear and fracture surface of after corrosion test of the blanks are given a magnification of $1000 \times$ in Fig. 7. In punching with eccentric press, the shear and fracture surface of the blank is more vulnerable to corrosion when compared to other punching techniques. The surface of blanks produced with HERF machine is observed to be less influenced by corrosion experiments. The SEM views of the blanks verify the graphics in Figs. 6, 7.
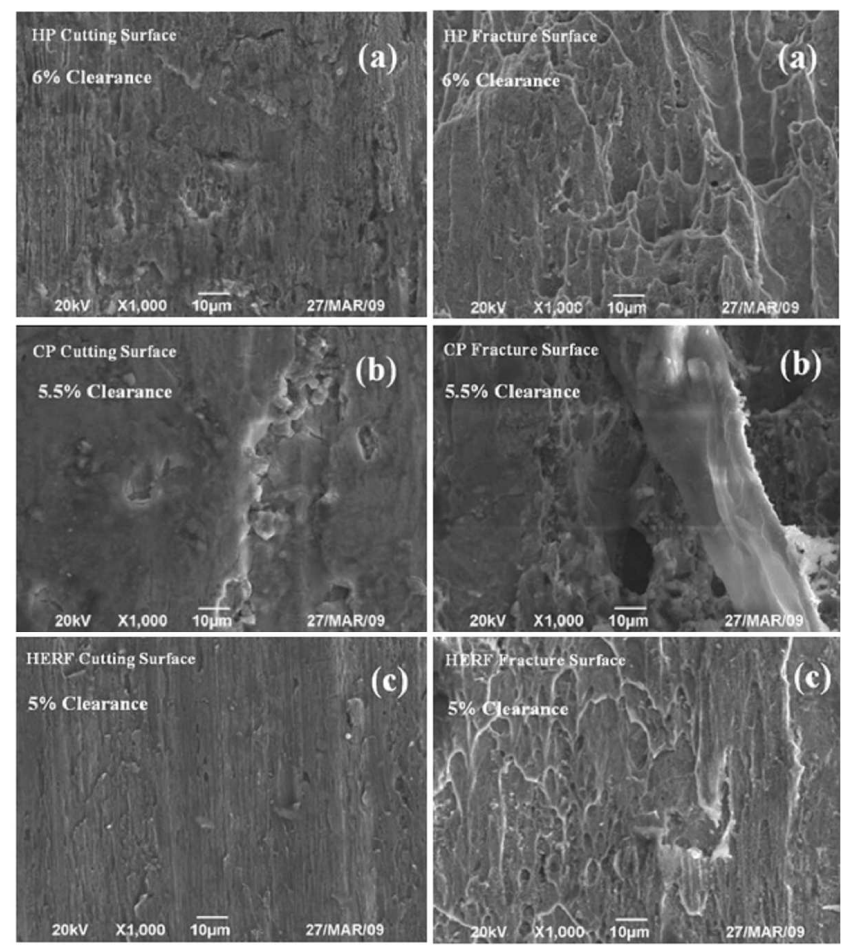

Fig. 7. SEM views of the shear and fracture surface of the blanks after corrosion test for (a) hydraulic, (b) conventional, (c) HERF.

When soft steels are put into natural aqueous solution, this leads to defects in oxide layer on the steel. This corrosion defects appear in dislocation networks or grain boundaries on steel surface as mechanical damage such as erosion and roughness. Each flaw in the steel in the electrolyte (solution) causes an anodic reaction. As a result, the formation of iron ions and free electrons occurs. These electrons flow into oxide film to get involved in the cathodic reaction on the film surface. This reaction requires the presence of oxygen dissolved in the electrolyte, and these results in the formation of hydroxyl ions.

\section{TABLE III}

The corrosion potential of all blanks.

\begin{tabular}{c|c|c|c|c}
\hline \hline Type of Press & \multicolumn{4}{|c}{ Clearance } \\
\hline & $4.5 \%[\mathrm{~V}]$ & $5 \%[\mathrm{~V}]$ & $5.5 \%[\mathrm{~V}]$ & $6 \%[\mathrm{~V}]$ \\
\hline HP & 0.7307 & 0.6784 & 0.6235 & 0.6157 \\
CP & 0.7908 & 0.7268 & 0.6432 & 0.7164 \\
HERF & 0.6889 & 0.5935 & 0.6052 & 0.6150
\end{tabular}

Literature [13-15] verifies that material's resistance to shear increases at high speeds and strain rates, and that 
at the same time temperature on sheared surface of soft steels increases to approximately $600^{\circ} \mathrm{C}$. Temperature of the blanks produced with HERF increases to stress relief annealing levels immediately after shearing and then cools to room temperature again. This eliminates substantially the residual stresses that form on the shear and fracture surfaces in blanking. Therefore, the corrosion potential of blanks produced with HERF appears to be higher.

Strain rates $\left(\mathrm{s}^{-1}\right)$ of blanks produced eccentric press are not high enough to increase the shear surface temperature to treatment temperature. At the same time, it is high enough to increase resistance against shear. Hence, compared to other blanks, the shear and fracture surface corrosion potential of the blanks produced with eccentric press seems to be low.

\section{Conclusion}

In this study, effect of blanking speed on quality and corrosion of mild steel shear and fracture surface has been investigated. The following conclusions are drawn:

High forming speed was achieved by using two-stroke internal combustion engine;

It was observed that blanking speed is very effective on the roughness of the shear and fracture surfaces. When the blanking speed increased, shear and fracture surfaces roughness of the blanks decreased drastically;

It was observed that the corrosion resistance of the HERF-cut specimen was better than those of the hydraulic-cut and conventional-cut specimens;

The best corrosion properties were obtained in the HERF cutting since the cutting speed formed the least roughness on the surface;

Corrosion potential was found to be higher in blanks produced with HERF in all the tried clearances.

\section{References}

[1] K.H. Shim, S.K. Lee, B.S. Kang, S.M. Hwang, J. Mater. Process. Technol. 155-156, 1935 (2004).

[2] G. Fang, P. Zeng, L. Lou, J. Mater. Process. Technol. 122, 249 (2002).

[3] Y.A. Khan, S.M. Ganesan, H. Valberg, P.T. Moe, A.W. Hansen, Int. J. Mater. Form. 1, 535 (2008).

[4] P. Picart, V. Lemiale, A. Touache, J. Chambert, in: Proc. VIIIth Int. Conf. on Comp. Plasticity CIMNE, Barcelona, Eds.: E. Onate, D.R.J. Owen, University Franche-Comté, Besançon 2005, p. 339.

[5] S.K. Shukla, A.K. Singh, I. Ahamad, M.A. Quraishi, Mater. Lett. 63, 819 (2009).

[6] J.D. Majumdar, B.R. Chandra, A.K. Nath, I. Manna, J. Mater. Process. Technol. 203, 505 (2008).

[7] S. Yaldız, H. Saglam, F. Unsacar, H. Isık, Mater. Des. 28, 889 (2007).

[8] R. Davies, S.M. Dhawan, in: Proc. 7th Int. Machine Tools Design Research Conf., University of Birmingham, 1966

[9] T.Z. Quazi, R. Shaikh, J. Mod. Eng. Res. (IJMER) 2, 4547 (2012).

[10] E. Kanca, Ph.D. Thesis, Institute of Science and Technology, Gaziantep Üniv., 2009.

[11] T. Amol, N. Rahul, B. Sagar, Int. J. Emer. Tech. Adv. Eng. 3, 2250 (2013).

[12] S.L. Semiatin, Forming and Forging, Vol. 14, ASM Handbook, 1988.

[13] A. Pardo, M.C. Merino, M. Carboneras, F. Viejo, R. Arrabal, J. Munoz, Corros. Sci. 48, 75 (2006).

[14] J.Y. Chen, G.P. Yu, J.H. Huang, Mater. Chem. Phys. 65, 310 (2000).

[15] F.M. El-Hossary, N.Z. Negm, A.M. Abd El-Rahman, M. Hammad, C. Templier, Surf. Coat. Technol. 202, 1392 2008). 